\title{
A ANTROPOLOGIA NUMA ERA DE CONFUSÃO*
}

\author{
David Maybury-Lewis
}

Quando a Anpocs me honrou com o convite para pronunciar uma conferência em seu encontro anual - convite que aceitei antes dos acontecimentos do último 11 de setembro - escolhi como título A Antropologia numa era de confusão. Certamente eu não fazia idéia naquele momento de quão sinistramente apropriado o título havia de se tornar. O ataque terrorista aos Estados Unidos mostrou dramaticamente - muito mais dramaticamente do que todos os nossos escritos sobre a globalização - o grau de confusão de nossos tempos. Essa confusão, ou melhor, essas confusões são acompanhadas, lamento dizer, pela confusão na antropologia. Tentarei, portanto, desemaranhar neste texto algumas delas.

Primeiro, para colocá-las em perspectiva, pedirei a meus leitores que pensem retrospectiva-

\footnotetext{
* Conferência pronunciada na abertura do XXV Encontro Anual da Anpocs, 2001. Tradução de Plínio Dentzein.
}

mente no começo da antropologia; que considerem o que ela tentou fazer e se pode continuar a fazê-lo. Tais reflexões são inevitavelmente idiossincráticas. Cada um de nós provavelmente reconstrói a história da antropologia de uma maneira diferente, mas acredito que exista consistência suficiente nessas genealogias para os propósitos muito gerais destas primeiras linhas.

Acredito que a antropologia emana de um impulso tão antigo quanto a humanidade, da curiosidade sobre os outros povos combinada com a introspecção a nosso próprio respeito, quem quer que acreditemos ser. Ela deriva da especulação sobre a natureza humana, sobre o que significa ser mulher ou homem, e de um desejo de entender a variedade da cultura humana.

Em minha reconstrução do início da antropologia, gosto de começar com Heródoto. Escolho-o como primeiro ancestral por causa de seu relativismo e considero o relativismo fundamental para a boa antropologia. Não me refiro ao relati- 
vismo do tipo "vale tudo" de que os antropólogos são às vezes injustamente acusados. ${ }^{1}$ Esse tipo de relativismo insistiria em que não podemos condenar as práticas de outros povos, por mais repreensíveis que as consideremos, na medida em que elas são aprovadas pelas culturas desses povos. Ao contrário, o tipo de relativismo que respeito no pensamento de nossos antecessores e contemporâneos é um relativismo que suspende o juízo sobre os costumes de outros povos para melhor compreender seus modos de vida e, tanto quanto possível, sem preconceitos. Este entendimento não se apressa em julgar, mas também não foge ao julgamento. Seu propósito é melhorar nossa capacidade de fazer julgamentos fundamentados.

Volto até Heródoto, portanto, por causa do relativismo de suas posições e também para nos ajudar a lembrar que o relativismo razoável não é uma invenção moderna. Tal relativismo, entretanto, sempre gerou oposição, mesmo na época de Heródoto. Para um pensador grego do século $\mathrm{V}$ a. C. era necessária uma notável tolerância para observar que os arquiinimigos dos gregos, os persas, consideravam seu próprio modo de vida superior ao daqueles. Além disso, em seu amplo levantamento dos povos do mundo antigo, Heródoto observa que toda sociedade tem suas próprias vantagens e desvantagens e que não deveríamos nos precipitar em julgar outros povos segundo nossos próprios padrões. Foi por isso criticado por Plutarco, acusado de simpatizante dos bárbaros.

É claro, então, que a batalha em torno do relativismo cultural no pensamento ocidental começou há muitos séculos. Este não é o lugar para remontar a história dessa luta contínua, mas cabe a nós, os estudiosos reunidos no encontro anual da Anpocs, lembrarmos, ainda que de passagem, o desafio específico que se apresentou aos pensadores do Velho Mundo com a invasão européia das Américas e o esforço deles para entender os povos e as culturas do Novo Mundo.

O célebre debate entre Las Casas e Sepúlveda na corte espanhola em 1550 reuniu uma vez mais os argumentos a favor e contra uma tolerância razoável em relação a outros modos de vida. Las Casas argumentava a favor da tolerância e apoiava-se nas posições de contemporâneos como Montaigne que, num famoso ensaio sobre canibalismo, chegou a assumir uma atitude relativista em relação a essa prática, observada na América do Sul e que costumava atrair a condenação mais dura da parte dos europeus. Ele dizia que os europeus, que se declaravam chocados pelo canibalismo, em realidade eram responsáveis por torturas e barbaridades piores, e resumia seu argumento dizendo: "Podemos assim chamar de bárbaros a esses povos em relação às leis da razão, mas não em relação a nós mesmos, que os ultrapassamos em todo tipo de barbaridade" (Montaigne, 1578 [1960], p. 215). ${ }^{2}$

Às posições de Las Casas e Montaigne opunham-se as de Sepúlveda e dos conservadores, que argumentavam que os invasores europeus das Américas eram demonstravelmente civilizados, ao passo que as populações nativas não o eram. Estas eram selvagens e deviam ser tratadas como tais. $\mathrm{O}$ espírito de Sepúlveda ainda vive e inspira os argumentos daqueles que mesmo hoje desprezam a capacidade dos povos indígenas e argumentam contra o reconhecimento de seus direitos.

Mas a tolerância fundamentada de Las Casas ganhava adeptos no século XVIII à medida que o racionalismo ganhava a Europa. Giambattista Vico acreditava que já era possível uma ciência da história. Enquanto isso, a expansão européia do final do século XVIII e início do XIX prenunciava a iminente possibilidade de uma ciência da sociedade ou pelo menos uma ciência das sociedades. Os imperialistas europeus conquistavam vastas extensões de território em todo o mundo e enviavam emissários para estudar os povos que neles viviam. Dados sobre a população da terra fluíam para escritórios coloniais, museus, sociedades científicas, organizações missionárias e grande número de instituições oficiais e não oficiais que tivessem interesse nos povos das colônias e, por extensão, nos povos do mundo "não civilizado". Esses dados eram logo analisados e ordenados "cientificamente" em termos da teoria social evolucionista que aplicava princípios neodarwinistas ao estudo da história e da sociedade humanas.

Um dos principais problemas com a teorização evolucionista era que ela tendia a eliminar a tolerância razoável em relação às outras socieda- 
des e a substituí-la pelo desdém evolucionista. Os evolucionistas sociais acreditavam possuir critérios científicos que lhes permitiam ordenar as sociedades num gradiente de menos a mais civilizadas. Não é de surpreender que classificassem as sociedades não ocidentais como as menos civilizadas, por comparação com as ocidentais, que não só eram as mais civilizadas, mas também, convenientemente, produziam os estudiosos que desenvolviam essas classificações.

Ao final do século XIX, essas classificações começavam a ser atacadas por uma nova geração de antropólogos que argumentavam que a teoria social evolucionista se baseava em inferências equivocadas extraídas de dados etnográficos pouco fidedignos. As conseqüências dessas inferências eram graves, pois davam apoio supostamente "científico" a classificações questionáveis e inerentemente racistas. Nos Estados Unidos, Franz Boas e seus discípulos eram os que insistiam na necessidade de um melhor trabalho de campo para dar base a uma antropologia cultural empiricamente fundada que, por sua vez, mostraria a debilidade das teorias sociais evolucionistas. Na Europa ocidental, uma nova geração de antropólogos também insistia em um melhor trabalho de campo a serviço de uma antropologia social científica que também desconfiava da teoria evolucionista. Mas os europeus, particularmente os antropólogos sociais britânicos, também tinham dúvidas sobre a antropologia cultural de Boas. Ocupavam-se, em vez disso, da análise da estrutura social. Pelo menos um de seus teóricos principais, A. R. RadcliffeBrown, referia-se à estrutura social como uma realidade concreta e observável, por contraste com a cultura, que considerava uma abstração vaga (Radcliffe-Brown 1940 [1965], p. 190).

O enfrentamento entre antropólogos culturais e antropólogos sociais estendeu-se por décadas em meados do século XX, mas foi eventualmente abandonado. Passou a ser, em geral, aceito que a antropologia cultural incluía o estudo da estrutura e que a antropologia social inevitavelmente se ocupava da cultura. De fato, a antropologia estrutural defendida por Lévi-Strauss ocupava-se das estruturas da cultura assim como das estruturas da sociedade. De maneira lenta, mas segura, os depar- tamentos de antropologia (como o de Oxford, onde obtive meu doutorado) mudaram os nomes de seus programas para refletir essa convergência.

Enquanto isso, a idéia de cultura passou a ser adotada por outras disciplinas e se tornou parte tanto do discurso acadêmico como do discurso popular. Nos últimos anos, a cultura parece estar em toda parte. As pessoas falam de "cultura corporativa", "cultura adolescente", "cultura da polícia" e assim por diante, quase ao infinito. É como se cada grupo ou categoria de pessoas tivesse uma cultura. Infelizmente, esse amplo interesse pela idéia de cultura, que poderia ter anunciado uma nova era em que o estudo da cultura ocupasse um lugar central nas ciências sociais e nas humanidades, surgiu exatamente quando os antropólogos começavam a ter sérias dúvidas sobre o conceito.

Essas dúvidas faziam parte de uma crítica geral das teorias, dos métodos e das conclusões antropológicas que se desenvolvia a partir dos movimentos conhecidos como pós-colonialismo e pósmodernismo, ou, resumindo, POCO e POMO. ${ }^{3} \mathrm{O}$ POCO observava que as análises de outras sociedades produzidas pelos antropólogos que trabalhavam em situações coloniais eram suspeitas porque manchadas pelas assimetrias e vieses da situação colonial. O POMO generalizava essa dúvida, argumentando que toda investigação antropológica estava manchada de maneira semelhante, a menos que tivesse sido realizada por estudiosos conscientemente pós-modernos. Em verdade, os pós-modernos mais estritos pareciam aproximar uma espécie de niilismo segundo o qual seria virtualmente impossível reunir dados confiáveis ou desenvolver análises confiáveis a partir deles.

A abordagem do POMO teve o mérito de tornar os antropólogos agudamente conscientes das fontes de distorções em seus próprios dados, especialmente aqueles relacionados com as circunstâncias sob as quais o trabalho de campo fora realizado e do relacionamento do investigador(a) com os povos que investigara. Mas se se concluir a partir disso que os dados antropológicos previamente coligidos seriam dúbios e que os futuros dados mais confiáveis seriam virtualmente impossíveis de coligir, isso claramente colocaria um problema sério e 
potencialmente letal para a antropologia. Se os métodos da antropologia, particularmente o trabalho de campo por meio do qual a disciplina se estabeleceu, são pouco confiáveis e a teoria antropológica está assim marcada na fonte, então não fica claro quais resultados ela poderia produzir nem por que as pessoas deveriam dar qualquer atenção ao que os antropólogos têm a dizer.

Foi no meio desse processo de introspecção e conscientização que o conceito central da antropologia - cultura - também começou a ser atacado. A cultura sempre foi notoriamente difícil de definir, mas a maioria dos estudiosos a concebia como um conjunto padronizado e coerente de idéias que constituíam a visão de mundo e de si mesmo de um dado povo. Entretanto, os críticos diziam que a cultura não era claramente demarca$\mathrm{da}$, tanto em termos conceituais quanto em termos demográficos. O que quer dizer que as idéias num sistema cultural não seriam necessariamente coerentes nem consistentes. Como conseqüência, também não seriam necessariamente sistemáticas, nem serviriam como modelo para o pensamento e a ação. Além disso, raramente se encontrariam grupos identificáveis e bem marcados de pessoas que vivessem segundo as idéias das culturas, sistemáticas ou não. As concepções antropológicas da cultura, assim argumentavam seus críticos, não davam conta da mudança ou da agência individual (ver Ortner, 1984). Não davam o peso devido às histórias subalternas (ver Trouillot, 1995). Chegavam a desumanizar o povo que aspiravam a entender (ver Abu-Lughod, 1991). Assim, a despeito do fato de que cultura era um conceito central da antropologia sociocultural, ele teria sido mal construído e mal utilizado pelos próprios especialistas que o empregavam. Eles não teriam analisado a cultura como processo, como debate, como campo de contestação. Não teriam levado na devida conta o fato de que as idéias de uma cultura se confundiam com as de outras culturas, assim como de que os portadores de uma cultura não eram um grupo claramente delimitado. Tais equívocos podem ser corrigidos. Aprendemos dos pós-modernistas uma nova autoconsciência que melhora nossas análises atuais, desde que recusemos que ela paralise nossa pesquisa. De modo análogo, pode- mos adotar uma nova abordagem à cultura que evite os erros do passado. O que não devemos fazer, acredito, é abandonar o termo de vez. Isso seria jogar fora o bebê com a água do banho.

Fiquei satisfeito ao ver que havia outros estudiosos que concordavam com esta posição e que defendiam a utilidade do conceito de cultura no debate organizado por Richard Fox e publicado na Current Anthropology em 1999. Acredito que se abandonássemos o conceito de cultura simplesmente teríamos de reinventá-lo. ${ }^{4}$ Cultura se refere, ainda que de modo impreciso, a algo central à vida e ao pensamento humanos e, portanto, a algo que deve ser importante para a antropologia. A maioria das pessoas acredita participar de um modo de vida, e isso é uma parte importante de sua identidade. Esse é um fato social que, como antropólogos, temos de nos esforçar por entender. Precisamos com efeito entender o que as pessoas pensam que é sua cultura e o que ela significa para elas. Isso não nos impedirá de analisar seus próprios equívocos, assim como não nos impediu de analisar os velhos equívocos antropológicos que dizem respeito à cultura. Não deve nos incomodar que as pessoas tendam a essencializar suas culturas. Ao contrário, aprendemos bastante sobre as pessoas a partir da natureza dessas essencializações.

Tenho uma certa simpatia pelo líder aborígine australiano mencionado numa palestra por Jonathan Friedman que disse ao antropólogo visitante: "Eu sou um essencialista e se você não gostar, suma-se" (exceto que a expressão que ele usou era mais picante que "suma-se"!). O fundamental é que as idéias das pessoas sobre seu modo de vida, o que é importante nele, quem o compartilha, aquilo sobre o que concordam ou discordam, se querem ou não mudá-lo e como, de quais os aspectos dele que aceitam ou estão ansiosos por livrar-se - todas essas e muitas mais são criticamente importantes. Essa informação nos diz quem elas pensam que são e o que isso significa para elas.

Isso é especialmente verdade dos povos indígenas, para os quais agora me volto, pois são e sempre foram uma preocupação central em minhas pesquisas e nos meus esforços no campo dos direitos humanos. É importante observar des- 
de o começo que povos indígenas não são simplesmente aqueles que chegaram primeiro a um dado território. Tal definição funciona muito bem em lugares como as Américas ou a Austrália, mas é insatisfatória na África e na Eurásia, onde diferentes populações se deslocaram entre territórios por centenas e mesmo milhares de anos. Uma definição melhor seria um povo que foi conquistado, subordinado e marginalizado por um Estado estrangeiro (ver Maybury-Lewis, 1997, pp. 6-7). Esses povos lutam em todo o mundo para manter suas culturas. Nas Américas, essa é um luta de quinhentos anos que ainda continua. É uma história amarga, mas também uma notável história de perseverança.

$\mathrm{Na}$ minha experiência, os povos indígenas têm idéias definidas sobre suas culturas e sobre o que constitui a essência delas, embora possam discordar, e discordar agudamente, sobre essas questões. Também na minha experiência, esses povos não se envergonham de dizer a estranhos que estão lutando pela sobrevivência cultural. E, no entanto, eles são hoje atacados com uma bateria de argumentos que tenta mostrar que sua sobrevivência cultural é, ao mesmo tempo, impossível e indesejável.

Filósofos como Michael Blake argumentam (Blake, 2000) que a sobrevivência cultural é impossível, dado que uma cultura está em mudança perpétua e não pode ser posta no congelador. Essa formulação é, contudo, condescendente e equivocada. A sobrevivência cultural não é uma coisa que nós, os poderosos, fazemos para outros, os menos poderosos. Não é questão de preservar a cultura de um povo como que num museu; com o corolário de que, se um povo perder ou abandonar certos traços culturais, sua cultura não terá sobrevivido. Em suma, a sobrevivência cultural não é a preservação cultural. Os povos nativos não perderam suas culturas quando abandonaram o arco e a flecha, assim como os norte-americanos não perderam a sua cultura quando abandonaram o cavalo e a charrete.

Sabemos que a cultura é um processo. Portanto, quando falamos de sobrevivência cultural, queremos dizer que os portadores da cultura controlam esse processo. Esse controle é invariavel- mente uma questão de grau. Quanto mais autonomia e mais capacidade o grupo tiver de administrar a mudança em lugar de ser destruído por ela, tanto maior a possibilidade de sobrevivência de sua cultura. O grupo certamente pode abandonar aspectos centrais de sua cultura. Em tais casos, muitas vezes é algo a ser debatido entre seus tradicionalistas e seus modernistas se a cultura está ou não sobrevivendo.

Blake avança outros argumentos que considero aqui porque são freqüentemente utilizados contra o direito dos grupos à sobrevivência cultural. Ele sugere que só os românticos e sentimentais lutam pela sobrevivência cultural. Já que a mudança é inevitável, as culturas desaparecem o tempo todo. Por que deveríamos lamentar isso? Pode até ser bom que as culturas que não podem competir com sucesso desapareçam e que as que sobrevivem se tenham mostrado as mais capazes numa espécie de competição neodarwinista.

Note-se que quando somos questionados sobre por que deveríamos lamentar se alguma cultura não sobrevive, estamos sendo questionados por que deveríamos lamentar se a cultura de outros povos não sobrevive. Normalmente nos preocupamos muito com nossa própria cultura e nosso próprio modo de vida, como deixaram claro as intensas discussões em todo o mundo depois do 11 de setembro. Além disso, é pouco provável que eu, que escrevo estas linhas, e você, que as lê, acordemos um dia num mundo em que não haja mais ninguém que fale nossa língua. E, no entanto, as línguas estão morrendo num ritmo notável. Das aproximadamente seis mil línguas ainda faladas no mundo, cerca de metade estão moribundas no sentido em que não são ensinadas às crianças. As cerca de três mil restantes podem estar reduzidas a 300-500 num futuro previsível. Trata-se de uma taxa de extinção de línguas que supera as estimativas dos biólogos mais pessimistas quanto à extinção de espécies.

A morte de uma língua e de uma cultura são desorientadoras para os indivíduos e empobrecedoras para a espécie humana. A diversidade cultural e a comunicação entre culturas são os recursos mais importantes da humanidade e devem ser encorajadas e não abandonadas como questões 
marginais. É importante lembrar que as culturas não desaparecem por causa das leis abstratas da história. São com muita freqüência subjugadas e destruídas. Não preciso descrever aqui as muitas maneiras pelas quais se tentaram destruir as culturas indígenas. Muitos livros foram escritos descrevendo os ataques às línguas e culturas de povos indígenas, descrevendo a ruptura de suas comunidades, a proibição de seus rituais, o rapto de suas crianças. Essas eram (e são) medidas clara e intencionalmente etnocidas que ainda são enfrentadas por organizações indígenas e pró-indígenas.

E o que dizer sobre medidas etno-suicidas? E sobre as mudanças que não são forçadas mas procuradas pelos povos nativos? E sobre a extinção da língua que resulta da assimilação dos nativos pelos Estados onde vivem? Tais tendências muitas vezes opõem tradicionalistas e modernistas, cada um dos lados argumentando que o seu é o melhor, quando não o único caminho para assegurar a viabilidade de seu modo de vida. A construção de cassinos é um desses casos e é uma questão intensamente debatida nos Estados Unidos. Defensores dos cassinos dizem que a renda que eles trazem garante a sobrevivência cultural das comunidades nativas que os operam. Os opositores afirmam que os povos indígenas estão fazendo a si mesmos com os cassinos o mal que os brancos não conseguiram fazer em 500 anos.

A defesa dos cassinos foi feita de maneira eloqüente por Patty Hoeft (1993), que mostrou como o cassino na reserva oneida em Wisconsin, Estados Unidos, fez a área reviver economicamente. Os lucros são investidos na região, de modo que as pessoas não precisam mais sair para encontrar emprego em outro lugar. Agora existem empregos entre os oneida tanto para os indígenas como para os não indígenas. A renda do cassino paga um centro comunitário, creches, escolas e centros de saúde, e também subsidia o departamento de polícia e casas e apartamentos para a crescente população do distrito. Certamente a experiência dos oneida com o jogo foi positiva, na medida em que não esmagou os nativos, que foram capazes de investir os lucros cuidadosamente e de maneira a reforçar a sociedade civil na reserva. Mas o debate continua. A longo prazo, o jogo vai afiançar a cultura de povos como os oneida ou acabará por destruí-la?

Os oneida são um caso benigno quando comparados com os enormes cassinos construídos pelos pequot mashantucket e pelos mohegans no Estado de Connecticut, Estados Unidos. Trata-se dos maiores cassinos do mundo e trouxeram rios de dinheiro que alteraram dramaticamente as vidas de todos os que viviam na vizinhança, que era uma parte tranqüila do Connecticut rural. Os cassinos também alimentaram uma reação contra os indígenas entre os não indígenas da área, o que resultou, entre outras coisas, em esforços incansáveis da parte dos residentes locais para impedir que outros grupos nativos, como os pequots orientais, recebessem reconhecimento federal como tribos indígenas.

Ao mesmo tempo em que os povos indígenas estão à procura de estratégias que permitam a sobrevivência de suas culturas, eles têm de enfrentar aqueles que insistem em que essa sobrevivência deve ser impedida, porque enfraquece o Estado.

Esse argumento assume várias formas. Em sua versão mais forte, sustenta que tolerar a sobrevivência cultural dos povos indígenas significa outorgar-lhes autonomia local, o que os levaria a separar-se do Estado. O argumento é uma grosseira falta de compreensão ou então é fruto de má fé (ver Maybury-Lewis, 2002, p. 32). A grande maioria dos povos nativos hoje não querem se separar dos Estados em que vivem. Em lugar disso, pedem autonomia limitada dentro desses Estados. Governos que invocam o espectro da secessão normalmente o fazem sabendo perfeitamente bem que isso não está em questão, porque não querem conceder aos nativos direitos dentro do Estado.

De modo alternativo, alguns governos afirmam que conceder direitos aos indígenas prejudica o Estado porque os povos indígenas "são obstáculos ao desenvolvimento". Isso também não é verdade. O que esse argumento oculta é que os povos indígenas reclamam o reconhecimento de seus direitos a certos recursos que outras pessoas gostariam de lhes tomar, o que é uma questão inteiramente diferente.

Finalmente, muitas vezes se diz que o reconhecimento dos direitos dos indígenas solapa o Estado porque este não pode tolerar "quistos étnicos" 
dentro dele. Esse é o clássico argumento conservador contra o pluralismo étnico e se baseia numa teoria do Estado ultrapassada. A visão iluminista do Estado imaginava que, na medida em que ele se modernizasse, protegeria os direitos individuais, encorajaria a liberdade, a igualdade e a fraternidade e assistiria à evaporação da etnicidade. E, no entanto, Estados modernos desse tipo nunca foram realizados, nem mesmo na Europa, que foi alguma vez considerada a vanguarda da modernidade. Em vez disso, há um reconhecimento crescente e amplo de que a supressão da etnicidade e a assimilação forçada de minorias em geral não funcionou. As Américas são um bom exemplo. Depois de quinhentos anos de insistência em que os povos indígenas deveriam fundir-se na sociedade circundante ou ser assimilados por ela, pela força se necessário, os países estão abandonando essa insistência e passam a proclamar-se multi-étnicos. Esse é especialmente o caso naqueles países em que a modernização e a construção da nação envolvem populações indígenas substanciais.

É significativo que as duas maiores nações das Américas que não se proclamaram multi-étnicas sejam os Estados Unidos e o Brasil. Isso aconteceu porque as populações indígenas dos dois países são marginais a suas identidades nacionais. Mas, embora esses países não se apressem em declarar-se multi-étnicos na lei, a verdade é que vivemos num mundo em que, virtualmente, todos os Estados são multi-étnicos de fato. A única diferença é que alguns deles o admitem e procuram acomodar as diferenças culturais dentro do Estado, enquanto outros o negam e procuram eliminar as diferenças culturais insistindo na assimilação. O século XX nos mostrou que a última estratégia raramente funciona. Ao contrário, ela serve para incubar o conflito étnico, que tenderá a irromper com mais virulência porque se tentava suprimi-lo.

O século XX inaugurou a era da confusão, cujos efeitos estamos sentindo agora no século XXI. Boa parte dessa confusão diz respeito à crise do Estado-nação, que foi solapado e ultrapassado ao mesmo tempo em que perdia muito de sua força e autoridade. Mas, quando as pessoas escrevem sobre a crise do Estado-nação, o que estão dizendo? Que ele está para desaparecer? Acho que não. É por que os Estados se afastaram do modelo iluminista? Mas sempre foi assim. É que se está fazendo um esforço em todo o mundo para repensar o Estado, para entender as novas relações entre nações e Estados e as novas relações que são tanto externas quanto internas ao Estado.

O Estado, como a cultura, deixou de ser bem delimitado e claramente definido. Não é claro quem pertence a ele. Também não é claro o que seus membros têm em comum, da mesma forma que são pouco claras a natureza e a amplitude de sua soberania. O Estado, enfim, está lutando para conter e controlar os fluxos de informação, dinheiro, pessoas e outros recursos que cada vez mais escapam à sua autoridade. Além disso, o Estado contemporâneo não mais compete principalmente com outros Estados. Agora ele tem de enfrentar redes de todos os tipos. As redes financeiras e dos negócios são as mais óbvias dentre elas. São as mais citadas nas discussões da globalização. Mas, aos poucos, vamos tomando consciência do fato de que outras redes, menos benignas, de traficantes de drogas, guerrilheiros e terroristas, vêm adquirindo influência crescente em períodos recentes.

Neste momento, os Estados Unidos estão em guerra com uma rede, cuja localização e membros são incertos. Enquanto isso, os dois lados afirmam agir em defesa de suas culturas. Cada um dos lados alude com grandiloqüência à sua civilização e proclama ter embarcado numa cruzada ou jihad. Acredito que esse é precisamente o tipo de emaranhado conceitual que os antropólogos devem tentar esclarecer.

Em primeiro lugar, não estamos diante de um "choque de civilizações" do tipo sugerido por meu colega de Harvard, Samuel Huntington (1993), ainda que (ou talvez precisamente porque) grande parte do público norte-americano e alguns "por dentro" de Washington pareçam acreditar que as coisas estão acontecendo exatamente como Huntington previu. Sua tese era a de que os principais conflitos do futuro não seriam ideológicos ou políticos, mas culturais. Esses conflitos seguiriam as linhas que separam as principais civilizações do mundo que seriam, segundo seu esquema, a ocidental, a confuciana, a japonesa, a islâmica, a hindu, a eslávica-ortodoxa, a latino-americana e possivelmente a africana. A tese foi criticada por especialistas, que observaram que há tanto conflito dentro das civilizações de Huntington 
quanto entre elas. Isso foi, por exemplo, claramente demonstrado no Afeganistão, onde as lutas mais intensas e brutais tiveram lugar entre muçulmanos de etnias diferentes e de diferentes orientações políticas. Os antropólogos e os historiadores têm qualificações especiais para fazer esse tipo de crítica à tese de Huntington, porque são especializados no detalhe local e podem mostrar as fraquezas das generalizações de Huntington.

Mas as futuras contribuições da antropologia podem ser mais importantes do que simplesmente insistir em que nosso conhecimento local derrube as generalizações de Huntington ou de qualquer outro teórico. A pesquisa antropológica é especialmente adequada para o que chamei de era da confusão. Os antropólogos já fazem pesquisas sobre as redes que são tão características dos nossos tempos. E, o que é ainda mais importante, os antropólogos estão qualificados e em boa posição para ampliar suas técnicas de pesquisa, que consistem em se concentrar no particular para iluminar o geral. O foco antropológico no particular é coisa sabida e, às vezes motivo de piada. Fomos muitas vezes criticados por sermos localistas ao mais alto grau, que só raramente e com dificuldade somos capazes de enxergar o quadro geral. Mas esse é um equívoco ultrapassado. Há muito tempo os antropólogos começaram a fazer suas análises no âmbito do Estado e à procura de entender os sistemas internacionais.

Hoje, e nesta era, a análise antropológica precisa tentar ser cada vez mais relacional. Sabemos que o entendimento antropológico começa no âmbito da comunidade com o conhecimento local. Já relacionamos esse conhecimento à maneira como as pessoas pensam e agem em suas culturas ou modos de vida. Além disso, e concordando com Huntington, precisamos estar atentos às civilizações com que as pessoas que estudamos se identificam. Em desacordo com Huntington, precisamos manter um certo ceticismo quanto à consistência e às propriedades causais das civilizações, do modo como já fazemos em relação à cultura. Ao mesmo tempo, nossas análises devem incluir os Estados que tentam pôr ordem nisso tudo e as redes que atravessam esses Estados.

É claro que o que acabo de esboçar é um empreendimento fantasticamente ambicioso, e é por isso que comecei o texto lembrando que a antropologia foi sempre extraordinariamente ambiciosa. Ela precisa continuar essa tradição e trazer sua análise clara e relacional para as categorias esmaecidas e desordenadas desta era de confusão. Agora, mais que nunca, é imperativo que a antropologia continue a fazer o que sempre fez, isto é, desenvolver a compreensão relativista de outras culturas e civilizações para promover a tolerância fundamentada. Acima de tudo, a antropologia deve intensificar o esforço que sempre fez de compreender as categorias que as pessoas utilizam para dar sentido a um mundo que parece estar enlouquecendo.

\section{NOTAS}

1 Para uma discussão do relativismo sério, ver Maybury-Lewis, 2002, pp. 126-127.

2 Utilizo neste trabalho a convenção segundo a qual uma data que consta como, por exemplo, 1578 [1960], indica que o item foi escrito em 1578 e que eu o cito de sua reprodução numa publicação de 1960.

3 Uma boa discussão dos motivos que incentivaram esta introspecção pode ser encontrada em Marcus e Fischer, 1986.

4 Brumann diz o mesmo em sua resposta na Current Anthropology, 1999, p. S24.

\section{BIBLIOGRAFIA}

ABU-LUGHOD, Lila. (1991), "Writing against culture", in R. G. Fox (org.), Recapturing anthropology, Santa Fe, School of American Research.

BLAKE, Michael. (2000), "Rights for people, not for cultures". Civilization.

BRUMANN, Christoph. (1999), "Writing for culture : why a successful concept should not be Discarded". Current Anthropology, 40, Supplement.

FOX, R. G. (1999), "Editorial: culture - a second chance?". Current Antbropology, 40, Supplement. 
HOEFT, Patty. (1993), "Gaming: the oneida experience". NativePeoples, out./nov./.dez.

HUNTINGTON, Samuel. (1993), The clash of civilizations?. Nova York, The Council on Foreign Relations.

MARCUS, George \& FISHER, Michael. (1986), Anthropology as cultural critique. Chicago, The University of Chicago Press.

MAYBURY-LEWIS, David. (1997), Indigenous peoples, ethnic groups and the State. Boston, Allyn and Bacon.

MONTAIGNE, Michel de. (1578 [1960]), "Of cannibals", in The complete essays of Montaigne, vol. 1, Nova York, Doubleday Anchor Books.

ORTNER, Shcrry. (1984), "Theory in anthropology since the sixties", in Comparative studies in society and history, pp. 126-166.

TROUILLOT, M.-R. (1995), Silencing the past: power and the production of history. Boston, Beacon Press.

RADCLIFFE-BROWN, A. R. (1940 [1965]), "On social structure", in Structure and function in primitive society, EUA, The Free Press. 


\section{A ANTROPOLOGIA NUMA ERA ANTHROPOLOGY IN DE CONFUSÃO \\ A CONFUSION ERA}

David Maybury-Lewis

\section{Palavras-chave}

Antropologia; Cultura; Sobrevivência cultural; Teoria antropológica.

\begin{abstract}
A Antropologia sempre procurou entender a natureza humana e as variedades da cultura humana. Esta tarefa ambiciosa enfrentou constantemente dificuldades teóricas e metodológicas. A teoria da evolução social foi apresentada como sendo preconceituosa e baseada em poucas evidências, inclusive com uma inferência racista em uma época de dominação européia. Os antídotos rigoroso trabalho de campo inspirado no funcionalismo, estruturalismo ou culturalismo - eram também vistos como contaminados por hierarquias de uma ordem mundial colonialista. A atenção pós-moderna a este "orientalismo" em um mundo pós-colonial produziu textos no sentido de atentar os antropólogos para estas questões, o que acarretou um declínio na produção e no entendimento antropológico. Esta conferência considera estes dilemas, os correntes debates sobre "cultura" e "sobrevivência cultural" e como antropólogos deveriam proceder nesta nova era de confusão, produzida pela globalização e pelo aparecimento do Estado-nação.
\end{abstract}

David Maybury-Lewis

\section{Keywords}

Anthropology; Culture; Cultural Survival; Anthropological Theory.

The study of anthropology has always tried to understand the human nature and the varieties of human culture. Such ambitious task has constantly faced methodological and theoretical difficulties. The socalled social evolution theory has been seen as both prejudicial and one that lacks enough evidence, having also some racist inference due to the European hegemony then. The antidotes - rigorous fieldwork inspired in functionalism, structuralism, or "culturalism" were also seen as contaminated by colonialist world order hierarchies. The post-modern attention to such "orientalism" in a post-colonial world has brought forth numerous papers that will help anthropologists pay due attention to such matters, which has caused a decline in both production and anthropological understanding. This conference takes in consideration these dilemmas, the current debates on "culture" and "cultural survival," and how anthropologists could proceed in such confusion era, confusion that comes as a result of globalization and the appearance of the idea of State-nation.

\section{L'ANTHROPÓLOGIE DANS UNE ĖRE DE CONFUSION}

David Maybury-Lewis

\section{Mots-clés}

Anthropologie; Culture; Survie culturelle; Théorie anthropologique.

L'anthropologie a toujours cherché à comprendre la nature humaine et la diversité de sa culture. Cette tâche ambitieuse a affronté, de manière constante, des difficultés théoriques et méthodologiques. La théorie de l'évolution sociale a été présentée comme faisant preuve de préjugés et fondée sur peu d'évidences. Elle même été présentée comme étant une interférence raciste dans une époque de domination européenne. Les antidotes - rigoureux travail de champs inspiré sur le fonctionnalisme, le structuralisme ou le culturalisme - étaient aussi compris comme étant contaminés par des hiérarchies d'un ordre mondial colonialiste. L'attention postmoderne à cet "orientalisme" dans un monde postcolonial a produit des textes en vue d'attirer l'attention des anthropologues sur ces questions, ce qui a déclenché un déclin de production et de la compréhension anthropologiques. Cette conférence prend en compte ces dilemmes ainsi que les débats courants à propos de la "culture" et de la "survie culturelle", et la manière par laquelle les anthropologues devraient procéder dans cette nouvelle ère de confusion, produite par la globalisation et l'apparition de l'État-nation. 